\title{
A concurrent assessment of schedule-induced aggression and schedule-induced polydipsia in the rat*
}

\author{
JOHN F. KNUTSON $\dagger$ and SUSAN P. SCHRADER $\dagger \dagger$ \\ University of Iowa, Iowa City, Iowa 52242
}

\begin{abstract}
Rats subjected to FI 60-sec and FI 120-sec schedules of reinforcement were permitted concurrent access to a licking tube and a restrained target rat. While both polydipsia and attack occurred, polydipsia was the predominant scheduleinduced behavior. When attack occurred, and the licking tube was also available, attack usually followed licking in the interreinforcement interval. Eliminating access to the target did not influence polydipsia, and removal of the licking tube did not affect the frequency of aggressive episodes.
\end{abstract}

When an organism is subjected to an intermittent schedule of reinforcement and suitable environmental arrangements are made, behavioral events other than the operants specified by the schedule reliably occur. If the environment includes a licking tube, schedule-induced polydipsia develops (Falk, 1961). If the environmental space includes a running wheel, schedule-induced wheel running is displayed (Levitsky \& Collier, 1968). When a conspecific is available, schedule-induced attack may result (Knutson, 1970). These and other schedule-induced phenomena, such as pica (Villarreal, 1967) have recently attracted considerable interest. Because of similarities among these behaviors, such as the temporal relationship to reinforcement, the development over sessions, and the often "excessive" nature, Falk (1972) has argued that they are all members of the same class, adjunctive behaviors. Similarly, Staddon and Simmelhag (1971) described these as "interim activities," which are members of a response class that develops under periods of low reinforcement probability, and they suggested that the behaviors are analogous to the ethologist's class of displacement behaviors.

In order to assess schedule-induced behaviors as a response class, Falk (1972) has recommended a strategy of research which would be directed towards a determination of the substitutability of the individual behaviors. While investigators have attempted a concurrent analysis of schedule-induced polydipsia and schedule-induced wheel running (e.g., Levitsky \& Collier, 1968; Segal, 1969), such research has not been done

\footnotetext{
*This investigation was supported, in part, by Biomedical Sciences Support Grant FR-07035 from the General Research Support Branch, Division of Research Resources, Bureau of Health Professions Education and Manpower Training, National Institutes of Health (awarded by the Office of the Vice-president for Educational Development and Research) and, in part, by funds made available by the Grad uate College of The University of Iowa. The assistance of Karen Boatman is gratefully acknowledged.

tR equests for reprints should be sent to John F. Knutson, Department of Psychology, University of Iowa, Iowa City, Iowa 52242 .

+ Now at Pennsylvania State University.
}

with schedule-induced aggression and schedule-induced polydipsia. Hymowitz (1971) investigated both schedule-induced aggression and scheduleinduced polydipsia in two experiments and concluded that schedule-induced attack and schedule-induced aggression may not be analogous behaviors. Recently, Keehn (1970) investigated schedule-induced polydipsia in a single rat while another untrained rat was also in the experimental chamber. While extensive consideration was given to the polydipsic behavior, no attack behavior was reported. Perhaps the lack of aggression in the Keehn (1970) study reflects an S-specific anomaly, or perhaps the opportunity to engage in licking supplanted aggression. The present study was an attempt to assess the relationship between schedule-induced aggression and schedule-induced polydipsia when both responses are concurrently available to the $S$.

\section{METHOD}

\section{Subjects}

Three experimentally naive 150 -day-old male hooded rats maintained at $80 \%$ of ad lib weight served as experimental Ss. They were paired with three experimentally naive male hooded target rats, of comparable weight, maintained on an ad lib feeding schedule. Additional naive male hooded rats were reserved as substitute targets to relieve targets sustaining tissue damage during aggression testing. All animals were ind ividually housed in $17.8 \times 24 \times 17.8 \mathrm{~cm}$ cages with free access to water. The colony room housing these rats was maintained on a 24-h light schedule.

\section{Apparatus}

The $35.5 \times 34 \times 21 \mathrm{~cm}$ experimental chamber was constructed of clear Plexiglas and a grid floor consisting of $0.2-\mathrm{cm}-\mathrm{d}$ iam stainless steel rods spaced $1.8 \mathrm{~cm}$ apart, center-to-center. A Gerbrands lever was located at the center of one wall, $5 \mathrm{~cm}$ above the floor. On the same wall, $5 \mathrm{~cm}$ to the left of the lever, was an acrylic foodcup. Forty-five-milligram Noyes-pellet reinforcers could be delivered to the food cup by a Lehigh Valley Model 114-20 pellet dispenser. When a licking tube was inserted into the chamber, it was located on the wall adjacent to the foodcup, $4.5 \mathrm{~cm}$ above the grid floor and $20.5 \mathrm{~cm}$ from the wall containing the lever and pellet dispenser. Licking on this tube was monitored, using a Lehigh Valley contact relay (drinkometer). 
Table 1

The Sequence of Experimental Manipulations and the Number of Sessions Required for Each Procedure for Each Subject

\begin{tabular}{|c|c|c|c|}
\hline Procedure & $\mathrm{S} 1$ & $\mathrm{~S} 2$ & S 3 \\
\hline Baseline: Original target and water bottle present & 5 & 5 & 5 \\
\hline Magazine training and shaping: No target; no licking tube & 1 & 2 & 3 \\
\hline FI 30: No target; no licking tube & 5 & 5 & 5 \\
\hline FI 60: No target; no licking tube & 11 & 11 & 10 \\
\hline FI 60: Original target and licking tube present & 9 & 31 & 8 \\
\hline FI 120: No target; no licking tube & 7 & 7 & 6 \\
\hline FI 120: Original target and licking tube present & 14 & 10 & 14 \\
\hline FI 120: Target rotation; second target and licking tube present & 5 & - & 5 \\
\hline FI 120: Target rotation; third target and licking tube present & 4 & - & 4 \\
\hline FI 120: Target rotation; original target and licking tube present & 4 & - & 6 \\
\hline FI 120: Original target present; no licking tube & 6 & 6 & 6 \\
\hline FI 120: Original target and licking tube present & 5 & 5 & 5 \\
\hline FI 120: No target; licking tube present & 5 & 5 & 5 \\
\hline FI 120: No target; no licking tube & 5 & 5 & 5 \\
\hline
\end{tabular}

When a target animal was present in the chamber, it was restrained in the corner farthest from the foodcup and opposite the licking tube. Target restraint was accomplished by using a Velcro and leather adjustable harness which encircled the neck and chest of the target rat. The harness was attached to a bead chain which could be secured to the corner of the chamber by passing it through a hole and attaching a clamp to the chain. When restrained in this manner, the target rat was free to stand up or move about, but it was unable to contact the lever, the foodcup, or the licking tube. In addition, the target rat could not physically interfere with the experimental animal while the latter was engaged in barpressing, eating, or licking. To prevent chewing on the restraining harness by the food-deprived experimental Ss, the leather harness had been soaked in a quinine solution prior to use.

The experimental chamber was enclosed in a $79 \times 79 \times 30 \mathrm{~cm}$ sound-attenuating chamber which was fitted with two observation windows, located on adjacent sides. A 10-W lamp provided continuous illumination. Scheduling of experimental events was accomplished by using conventional electronic timers and relay circuitry. Data were recorded on electromechanical counters and cumulative recorders.

\section{Procedure}

Prior to magazine training, each food-deprived $\mathrm{S}$ was placed in the chamber with both the licking tube and restrained target in the chamber for five 50-min sessions. Trained observers recorded occurrences of aggressive behavior. Aggression was defined as physical contact between the target and experimental $\mathrm{S}$. This contact was characterized by striking while in the stereotyped aggressive posture (Ulrich \& Azrin, 1962), biting of the target by the experimental $S$, or vigorous pawing upon the head of a supine target rat (Baenninger \& Grossman, 1969).

After these five baseline sessions, the target rat and licking tube were removed from the chamber and the experimental Ss were magazine-trained and shaped to barpress by the method of successive approximations. Following acquisition of the barpress response, the Ss were subjected to a fixed-interval 30-sec (FI 30) schedule of reinforcement for five sessions; the schedule was then changed to FI 60-sec. Each session consisted of 50 reinforcer presentations. When the barpress responding reflected a scalloped pattern and the overall response rates for five sessions did not deviate more than $7 \%$ of the mean of those sessions, the restrained target and the licking tube were returned to the experimental chamber.

After 8-31 sessions at FI 60-sec, the target and water bottle were again removed and the schedule requirement was changed to FI 120-sec. Similar to the Hawkins, Schrot, Githens, and Everett (1972) schedule-induced polydipsia procedure, the number of reinforcements per session was reduced proportionally to the interval increase. Each session at FI 120-sec consisted of the length of time requiring 25 reinforcer presentations. After responding stabilized on the FI 120 -sec schedule, the restrained target and licking tube were reintroduced for 10-14 sessions.

Because individual pairings have influenced the occurrence of shock-induced aggression in rats (Powell, Francis, Braman, \& Schneiderman, 1969) and because target rotations during schedule-induced aggression with pigeons exerted a potent influence on attack in a recent study in this laboratory (Knutson, 1973), Ss 1 and 3 in this study were paired with substitute targets during nine sessions. Ss 1 and 3 were then re-paired with their original targets for an additional four and six sessions, respectively.

During the next phase of the study, each $S$ was tested with the original restrained target present, but the licking tube was removed from the chamber. Then, following another series of sessions with both the target and water bottle present in the chamber, a series of sessions was completed with the licking tube present and the target removed. The final seties of sessions consisted of a reassessment of the barpress response, with both the targets and the licking tube removed from the chamber. Table 1 indicates the sequence of experimental manipulations and the number of sessions required for each $S$ during each experimental manipulation.

\section{RESULTS}

All three Ss displayed attack responding and licking when the experimental chamber permitted the occurrence of those responses. While both behaviors occurred, differences between licking and attack were apparent, as were individual differences among Ss with respect to those behaviors. Figure 1 shows the number of attack episodes, lick responses, and barpresses for each $\mathrm{S}$ during each session. The barpress response reflected a generally high degree of stability across sessions for all Ss, and this operant was not disrupted by the presence of the targets or the licking tube. In addition to the overall rate stability, the temporal patterning of responding reflected by scalloping in the interreinforcement interval was maintained throughout the experiment.

Schedule-induced polydipsia began to emerge during the first aggression and licking test session following 

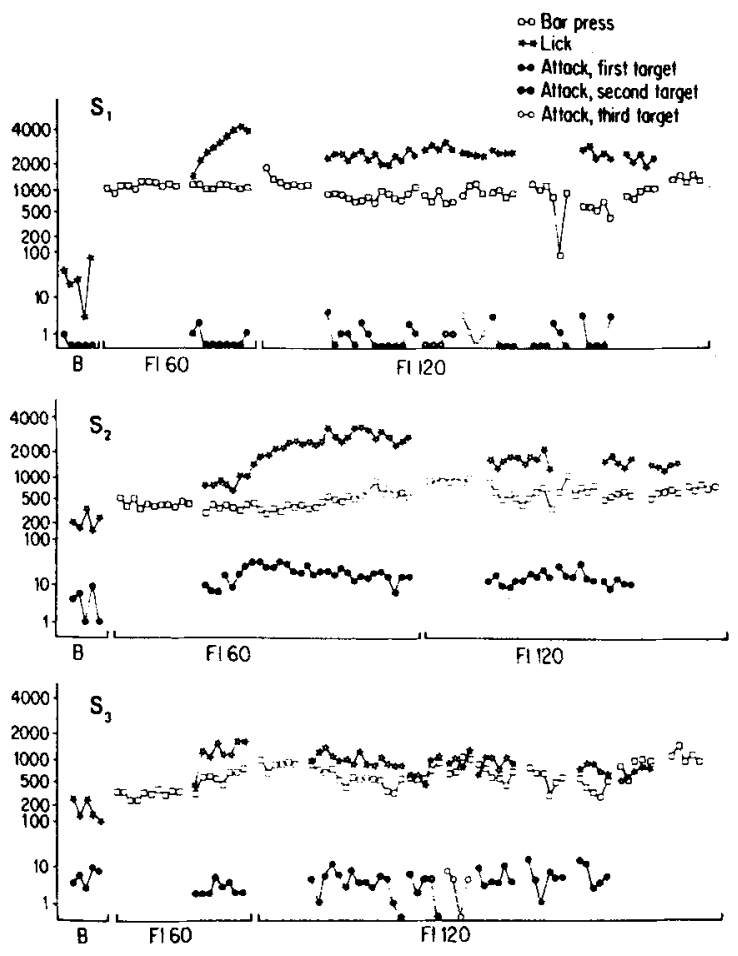

Fig. 1. The number of barpress responses, licks, and attack episodes during the five baseline (B) sessions and the FI 60-sec sessions and the FI 120-sec sessions. The use of a log scale on the ordinate permits the presentation of all three responses for each $S$ on the same graph.

training. It increased in frequency during successive sessions until it occurred at the high and relatively stable rate which persisted during most test sessions. The schedule-induced polydipsia showed a slight decrease in overall rate when the schedule was changed from FI 60-sec to FI 120-sec, but the number of licks per reinforcement was increased. Neither target rotations (with Ss 1 and 3), nor target removal, resulted in any systematic change in the overall frequency of licking behavior. Although the three Ss differed with respect to rates of licking behavior, all displayed high rates, and all rates were much higher than during the pretraining baseline sessions. The similarity in barpressing and licking among Ss was not reflected in the attack behavior.

Aggression was generally characterized by brief bouts of boxing while in the stereotyped posture, although instances of experimental Ss biting targets were also observed. Only S 2 evidenced a stable frequency of attack that regularly exceeded the frequency of attack during the baseline. While both Ss 1 and 3 occasionally displayed attack frequencies which exceeded the baseline, generally the number of bouts per session were no more than during baseline. The target rotations accomplished with Ss 1 and 3 did not alter the fighting frequencies. For all Ss, the duration of fighting bouts during baseline was usually quite short $(2-3 \mathrm{sec})$, while the attack episodes occurring during the FI schedules were often as long as 6-7 sec. The longer bouts were the ones most often associated with biting. Just as the frequency of licking was not appreciably influenced by the shift from FI 60-sec to FI 120-sec, the overall attack frequency did not change with the schedule shift, but the number of aggressive episodes per reinforcement increased. For both FI 60 -sec and FI 120 -sec, virtually all attacks occurred within the first $70 \%$ of the session.

In addition to the overall frequency of attack and licking displayed per session, the data were examined in terms of the distribution of attack and licking in the interreinforcement interval, and of the sequential relationship between licking, attack, and responding. Both attack and licking episodes were individually categorized on the basis of whether the response was postreinforcement and within $12 \mathrm{sec}$ of reinforcement (post- $S_{1}^{\mathbf{R}}$ ), postreinforcement but more than $12 \mathrm{sec}$ after reinforcement (post- $\mathrm{S}_{2}^{\mathrm{R}}$, or postresponding. In addition, lick/attack sequences, attack/lick sequences, and episodes of licking and attacking intermixed with responding (MIX) were noted. Table 2 indicates the percentage of interreinforcement intervals characterized by those categories of behaviors, as well as the percentage of interreinforcement intervals when only barpressing was recorded. With respect to polydipsia, it is apparent that licking was predominantly postreinforcement, and primarily post- $S_{1}^{R}$, whether or not a target rat was present. When a licking tube and a restrained target were both present in the chamber, postreinforcement, postresponding, and postlicking attack were observed. However, most of the attack under that condition followed licking. In addition, virtually all attack in the MIX category was preceded by licking. Removal of the licking tube resulted in most attack occurring in the post- $S_{2}^{\mathrm{R}}$ and the postresponding categories. During all sessions following training, Ss 1 and 3 displayed a single episode of licking prior to the first reinforcement, and these rats never displayed attack prior to the first reinforcer presentation. During the postbaseline sessions, S 2 displayed only two attack episodes but no licking prior to the first reinforcer presentation.

Although Fig. 1 and Table 2 indicate that considerable licking and a large number of attacks occurred, these two responses and barpress responding did not always fill the interreinforcement intervals. Periods of time not associated with these three recorded behaviors regularly occurred in all Ss at both FI $60-\mathrm{sec}$ and FI 120 -sec.

In summary, licking was reliably displayed at a high rate by all Ss, whereas only one S consistently displayed high frequencies of attack. When both licking and at tack could occur, licking was predominantly a postreinforcement phenomenon, while attack, when it occurred, usually followed licking. 
Table 2

Percentage of Interreinforcement Intervals With Categories of Attack, Licking, Attack/Licking Sequences

\begin{tabular}{|c|c|c|c|c|c|c|c|c|c|c|c|}
\hline & arget and & & Attack & & & Licking & & Seque & ences & & \\
\hline $\begin{array}{r}\text { Lic } \\
\text { Schedule }\end{array}$ & $\begin{array}{l}\text { cking Tube } \\
\text { Avail- } \\
\text { ability }\end{array}$ & Post-S $\mathbf{S}_{1}^{\mathbf{R}}$ & Post-S ${ }_{2}^{R}$ & Post-R & Post-S ${ }_{1}^{\mathbf{R}}$ & Post-S ${ }_{2}^{\mathrm{R}}$ & $\begin{array}{c}\text { Post } \\
\text { Respond- } \\
\text { ing }\end{array}$ & $\begin{array}{c}\text { Licking } \\
\text { Attack }\end{array}$ & $\begin{array}{l}\text { Attack/ } \\
\text { Licking }\end{array}$ & MIX & $\begin{array}{c}\text { Bar- } \\
\text { pressing } \\
\text { Only }\end{array}$ \\
\hline Subject 1 & & & & & & & & & & & \\
\hline FI 60 & $T_{1} L$ & 0.2 & 0.2 & 0.2 & 70 & 2.5 & 11 & 0 & 0 & 0.2 & 15.7 \\
\hline FI 120 & $\mathrm{~T}_{1}^{2} \mathrm{~L}$ & 0.9 & 0 & 0.9 & 75 & 0.9 & 7.3 & 0.7 & 0.9 & 1.9 & 11.5 \\
\hline FI 120 & $T_{2}^{2} L$ & 1.6 & 0 & 0 & 88 & 0 & 1.6 & 0 & 0 & 2 & 6.8 \\
\hline FI 120 & $\mathrm{~T}_{3} \bar{L}$ & 1 & 0 & 0 & 81 & 0 & 8 & 2 & 0 & 1 & 7 \\
\hline FI 120 & $\mathrm{~T}_{1} \mathrm{~L}$ & 1 & 0 & 0 & 89 & 1 & 2 & 1 & 0 & 0 & 6 \\
\hline FI 120 & $T_{1}$ & 2.6 & 0 & 1.8 & - & - & - & - & - & - & 95.6 \\
\hline FI 120 & $\mathrm{~T}_{1} \mathrm{~L}$ & 0 & 0 & 0 & 84 & 0 & 2.5 & 0.8 & 0 & 2.5 & 10.2 \\
\hline FI 120 & $\mathrm{~L}$ & $\theta$ & $\theta$ & $\theta$ & 79 & 2.5 & 5 & 0 & 0 & 0 & 13.5 \\
\hline Subject 2 & & & & & & & & & & & \\
\hline FI 60 & $\mathrm{~T}_{1} \mathrm{~L}$ & 0.9 & 2 & 1.4 & 44 & 9 & 6 & 14 & 0.3 & 6 & 16.4 \\
\hline FI 120 & $\mathrm{~T}_{1}^{2} \mathrm{~L}$ & 0 & 0 & 1.3 & 59 & 3 & 3 & 13.7 & 0 & 19 & 1 \\
\hline FI 120 & $T_{1}$ & 1.6 & 15.7 & 14 & - & - & - & - & - & - & 68.7 \\
\hline FI 120 & $\mathrm{~T}_{1}^{+} \mathrm{L}$ & 0 & 0 & 0.8 & 61 & 5.4 & 0 & 19 & 0.8 & 10 & 3 \\
\hline FI 120 & $\mathrm{~L}^{2}$ & - & - & - & 58 & 12 & 15.4 & - & - & - & 14.6 \\
\hline Subject 3 & & & & & & & & & & & \\
\hline FI 60 & $T_{1} L$ & 1.5 & 1.5 & 1 & 28 & 13 & 11 & 0.5 & 0 & 1 & 42.5 \\
\hline FI 120 & $\mathrm{~T}_{1} \mathrm{~L}$ & 0.3 & 0.6 & 2.5 & 40 & 8 & 12 & 3.5 & 0 & 7 & 26.1 \\
\hline FI 120 & $\mathrm{~T}_{2} \mathrm{~L}$ & 0 & 0 & 3.5 & 23 & 11 & 16 & 0 & 0 & 4 & 42.5 \\
\hline FI 120 & $\mathrm{~T}_{3} \mathrm{~L}$ & 0 & 0 & 3 & 27 & 11 & 11 & 6 & 0 & 3 & 39 \\
\hline FI 120 & $\mathrm{~T}_{3} \mathrm{~L}$ & 0.7 & 0 & 1.5 & 38 & 5 & 7 & 0.7 & 0 & 10 & 37.1 \\
\hline FI 120 & $\mathrm{~T}_{1}$ & 0 & 10 & 12 & - & - & - & - & - & $1 *$ & 77 \\
\hline FI 120 & $\mathrm{~T}_{1} \mathrm{~L}$ & 0 & 8 & 1.6 & 36 & 8 & 0.7 & 6 & 0.7 & 4 & 35 \\
\hline FI 120 & $\mathrm{~L}^{2}$ & - & - & - & 30 & 8 & 12 & - & - & - & 50 \\
\hline
\end{tabular}

*Post- $S_{2}^{R}$ and post-R sequences.

\section{DISCUSSION}

In terms of overall frequencies and the percentage of interreinforcement intervals characterized by the respective responses, schedule-induced polydipsia had a much higher probability of occurrence than schedule-induced aggression. This seems to hold whether the two responses were concurrently available to the rat, or whether the assessment of the behaviors was accomplished individually. These results are consistent with the data reported by Hymowitz (1971). In view of the fact that the target removal exerted little influence on the frequency of licking, and the licking tube removal exerted little influence on the frequency of attack, it seems unlikely that these two behaviors are interchangeable. The large number of interreinforcement intervals without at tack when the licking tube was not present underscores this point. Thus, it seems that the Falk (1972) recommendation of an assessment of substitutability supports the Hymowitz (1971) conclusion that the two phenomena may not be directly analogous.

The pattern of licking, attack, and responding in the interreinforcement interval is similar to the pattern of licking, wheel running, and responding reported by Levitsky and Collier (1968) and Segal (1969). That is, licking generally preceded attack in this study, and licking preceded running in the Levitsky and Collier
(1968) and Segal (1969) studies. In the Staddon and Simmelhag (1971) analysis of interim activities, the patterning of interim responses and the terminal response was described as nearly always following a fixed sequence. While each recorded response did not always occur in each interreinforcement interval, Staddon and Simmelhag (1971) indicated that when they did occur, they usually occurred in the same relative order. Although the predominant interreinforcement response pattern in the present study followed a fixed sequence, that sequence was not invariant since occasionally attack preceded licking and, more often, licking and attack were imbedded between bursts of barpressing. Thus, while these data do not follow the Falk (1972) analysis of adjunctive responding, the data are not inconsistent with the Staddon and Simmelhag (1971) discussion of interim activities.

\section{REFERENCES}

Baenninger, R., \& Grossman, J. C. Some effects of punishment on pain-elicited aggression. Journal of the Experimental Analysis of Behavior, 1969, 12, 1017-1022.

Falk, J. L. Production of polydipsia in normal rats by an intermittent food schedule. Science, 1961, 133, 195-196.

Falk, J. L. The nature and determinants of adjunctive behavior. In R. M. Gilbert and J. D. Keehn (Eds.), Schedule effects: Drugs, drinking, and aggression. Toronto: University of Toronto Press, 1972. Pp. 148-173.

Hawkins, T. D., Schrot. J. F., Githens, S. H., \& Everett, P. B Schedule-induced polydipsia: An analysis of water and alcohol ingestion. In R. M. Gilbert and J. D. Keehn (Eds.), Schedule 
effects: Drugs, drinking, and aggression. Toronto: University of Toronto Press, 1972. Pp, 95-128.

Hymowitz, N, Schedule-induced polydipsia and aggression in rats. Psychonomic Science, 1971, 23, 226-228.

Keehn, J. D. Schedule-induced licking and polydipsia Psychological R eports, 1970, 26, 155-161.

Knutson, J. F. Aggression during the fixed-ratio and extinction components of a multiple schedule of reinforcement. Journal of the Experimental A nalysis of Behavior, 1970, 13, 221-231.

Knutson, J. F, Aggression as manipulatable behavior. In J. F. Inutson (Ed,), Control of aggression: Implications from basic research. Chicago: Aldin-Atherton, 1973. Pp. 253-295.

Levitsky, D., \& Collier, G. Schedule-induced wheel running. Physiology \& Behavior, 1968, 3, 571-573.

Powell, D. A., Francis, J., Braman, M. J., \& Schneiderman, N. Frequency of attack in shock-elicited aggression as a function of the performance of individual rats. Journal of the
Experimental Analysis of Behavior, 1969, 12, 81 7-823.

Segal, E. F. The interaction of psychogenic polydipsia with wheel running in rats. Psychonomic Science, 1969, 14, 141-142, 144.

Staddon, J. E. R., \& Simmelhag, V. L. The "superstition" experiment: A reexamination of its implications for the principles of adaptive behavior. Psychological Review, 1971, $78,3-43$.

Ulrich, R. D., \& Azrin, N. H. Reflexive fighting in response to aversive stimulation. Journal of Experimental Analysis of Behavior, 1962, 5, 511-520.

Villarreal, J. E. Schedule-induced pica. Paper read at Meeting of Eastern Psychological Association, Boston, A pril 1967

(R eceived for publication A ugust 22, 1973; accepted March 26, 1974.) 